\title{
Study on Sino-Foreign Aesthetics Differentiation of Modern Design in Recent 30 Years (1985-2015)
}

\author{
Xiaodong Yuan \\ Zhengzhou University of Aeronautics \\ Zhengzhou, China 450007
}

\begin{abstract}
From the research status of the design ideas and design theory of China's modern industry, we can see that there are many who spread the ideas and theory popularized in the world, while few research in-depth the regional cultural attribute that influences design development; there are many who copy foreign cases directly from the perspective of application, while few explore in detail the design elements using subject professional knowledge; there are many who evaluate a design from the perspective of other industries in the society, while few lead the reform of social aesthetics mechanism using the design rules. This paper has presented the problems exist in design ideas and theory development of China' modern industry since the movement of "1985 Art Trend" from the perspective of differentiation using comparative method against this situation. Meanwhile, taking the excellent design ideas and design theory of modern industry developed in foreign countries in this period as a comparison object, the differences exist in industrial design ideas and design theory of China and other countries in recent 30 years (1985-2014) have been found out systemically. And the contents that are good for development of China's design ideas and design theory have been gained therein, thus excellent research achievements have been accumulated for national development under the condition of "Industry 4.0" nowadays.
\end{abstract}

Keywords-30 years of Sino-foreign development; design aesthetics; differentiation

\section{INTRODUCTION}

Relevant departments, enterprises and institutions at various levels and of various categories begin to pay attention to research of modern design aesthetics one after another in recent years. Meanwhile, an agreement has been reached about this point that comprehensive research of problems in modern design aesthetics is in relation to transforming "Made in China" to "Create in China", with a profound awareness that in order to make China's design industry progress greatly, it is a must to sum up previous experience, find out problems by comparison in the world, and abandon some ideas that hinder China's design industry to take off, with the theory research of modern design aesthetics as the base and the advanced foreign design cases and modern design aesthetic ideas as references.

Fund Programs:Humanistic and Social Science Research Project by the Education Department of Henan Province 2016, №2016-QN335

\section{RESEARCH STATUE OF CHINA's MODERN DESIGN AESTHETICS DEVELOPMENT}

China's modern industrial design aesthetics has developed for 30years since Professors Liu Guanzhong and Wang Mingzhi returned home country after learning abroad to engage in teaching research of China's modern design in 1984, and has been equipped with various conditions for researching of this project. Currently, comprehensive researches on differentiation problems of domestic modern industrial design aesthetics mainly fall into the following aspects.

Analysis the problems exist in modern design aesthetics in terms of design application and put forward specific improvement measures, for example, the "Design Methodology" [1] of Mr. Liu Guanzhong, a leader in China's design field, and Professor Yin Dingbang, "Design Aesthetics"[2] of Professor Xu Hengchun, and "Design \& Art Aesthetics"[3] of Professor Zhang Liguo. And Professor $\mathrm{Xu}$ Hengchun and Professor Zhang Liguo are the representatives who have promote China's design aesthetic theory reform at present, and have promote the research on Theory of Ontology and Internal Cause of aesthetic basic theory and design morphology to the research on External Cause Transformation Theory that brings about essential affect of design. Though summarizing and analysis of application of China's existing design aesthetics, those experts have pointed out that the main problems exist in China's design aesthetics development are as follows: shortage of comparative information resources of design, insufficient development of aesthetics theory in-depth, weak awareness of design service, lack of feature and low public aesthetics recognition on design works resulted by the above reasons. Meanwhile, experts have offered such optimized guiding suggestion that in order to enrich basic theory research of modern design aesthetics, we shall find out existing subjective defect on the basis of external objective reasons of design aesthetics.

Conduct comparison and analysis on foreign aesthetic theory research and design aesthetics application research. The works of outstanding personages on this level such as Chinese and Western Aesthetics and Cultural Spirit of Professor Zhang Fa, Director of Institute of Aesthetics, Renmin University of China, Aesthetics and Design of Professor Li Leshan, as well as Chinese and Western 
Civilization and Contemporary Chinese Design of Mr. Kan Tai-Keung, a world famous designer form Hong Kong, have put forward the reasonable and speculative suggestion through research that we should consider a lot in the development of China's artistic creation and design art, and in facing of western cultural thoughts and relevant aesthetics theories.

Conduct a systemic organization for modern design aesthetics theory. Take mature principles, ideas and methods of modern design aesthetics both at home and abroad as references to conduct discussion through example. For instance, such works as "Modern Design Aesthetics" of Professor Zhang Liguo and "Discussion on Value Characteristic and Development of Modern Design Aesthetics" of Professor Huang Qiangling have described various developments of modern design aesthetics from the aspect of actual application value of modern design aesthetics.

A general project of "Western Visual Form Research: From Formal Ontology to Meaning and Context" funded by National Social Science Funds in 2013, and general project of "Research on Development Trend and Application of Chinese Style Design" funded by National Social Science Funds in 2014 have conducted researches on development status of current aesthetics as well as modern artistic creation and design from perspectives of Chinese and Western aesthetics cognition respectively.

\section{RESEARCH CHARACTERISTICS OF MODERN DESIGN AESTHETICS DEVELOPMENT OF FOREIGN COUNTRIES}

The design field in foreign countries has made definition for Modern Design Aesthetics from such different perspectives as philosophy, physical anthropology, social anthropology, culturology, art, economics and the modern technical science development since 1980s, and has published a series significant research achievements.

Generally, researches on modern design aesthetics of foreign countries mainly concentrate on establishment of research on basic theory of design aesthetics based on such disciplines as philosophy and art, as well as modern technical science, and discussion of application value of above mentioned multi disciplines in design aesthetics theory construction."Extraordinary Origins of Everyday Things"consisting of various facts and cases complied by C.Panati in 1989 is of representative significance. And till now, many foreign scholars in design science all regard this book as a classic work representing development and research of modern design science. "Human Memory:Theory and Practice" [10] by Baddeley,A.D and "the end of modernity" [11] by Gianni Vattimo have put forward theoretical construction contents of design which is a academic research field newly emerged at that times from the perspectives of philosophy and sociology as well as on the level of art and science. Some other scholars have laid emphasis of research on aesthetics and design psychology within the scope of modern scientific development, as well as comprehensive system of multi-cross economics, and try to discuss the application value exists in modern design aesthetics and the acceptable contents and conditions of public aesthetic appreciation of modern design aesthetics. "design psychology . I 、 II" by Donald Arthur Norman, one of the founders of Nielsen Norman Company is quite famous among the above mentioned. While "Don't Make Me Think" by Steve Krug among another large number of modern young designers, has put forward personal view about design aesthetics at present times using such words with strong impact to vision and thought. As circumstantial evidence for establishing a research subject, what need to be pointed out is that Ikko Tanaka, a leader in Japanese design field, who has been influenced by American design aesthetics theory since 1950s and 1960s, and the older generation of Japanese designers with Ikko Tanaka as a representative, as well as such large number young designers as Kashiwa Sato, have listed the differentiation of east and west development in design aesthetics in recent years as the primary content of the researches on Japanese design aesthetics theory currently.

In conclusion, we need to make the systemic research on comparability of design aesthetics even better at present, and need a further progress in-depth. For theory research on design aesthetics, we should not stay on the level of summary and conclusion of design phenomena, yet we shall conduct the research from phenomenon to problems conclusion, and to strategy presenting, till presentation of complete strategy system, and provide theoretical and practical guidance for China's design science development. Only by this, can China's design be really recognized in the world.

\section{SINO-FOREIGN MODERN DESIGN DIFFERENTIATION IN RECENT 30 YEARS}

There is significant difference existing in the development of modern design in China and other countries in recent 30 years. Firstly, in terms of judgment on design artistic aesthetics, the common characteristics of design in China and other countries is pursuing of harmony. However, western aesthetics that pays more attention on reproduction mainly reflected as harmony of object formal elements, namely formal beauty; while Chinese aesthetics that pays more attention on expression mainly reflected as harmony of subject psychical elements, namely connotation beauty. As a result, their reflection on design is different; for example, westerners hold the opinion that natural beauty has flaws in terms of garden design, and to avoid this defect to achieve perfect, natural beauty must be enhanced via some certain kind of concept, to obtain art beauty, namely formal beauty.

Philosopher Pythagoras has explored harmony form the perspective of mathematics as early as Ancient Greek, and has put forward Golden Ratio. In the period of Renaissance, such people as Leonardo da Vinci and Michelangelo have proofed the rule of formal beauty through human body, while Hegel has made an abstract conclusion of the formal beauty rule of orderliness, uniform, balance, symmetry, in line with law and harmony taking external beauty of abstract form as a proposition. Thus the rule of formal beauty is rendered a considerable generality. It dominates such visual 
arts as architecture, drawing and sculpture, and it even influences significantly the auditory art as music and poetry. Scene and emotion grasp attention in building gardens in China. Absolutely, scene belongs to the category of physical form, but the measurement standard for it is to see whether it can be used to arouse people's emotions, thus to make an atmospheres of poetic illusion, namely artistic conception, which is different from the formal beauty pursued in western garden making. Secondly, western countries are skilled in linear, individual and mechanical thinking mode in terms of design thinking, which pays attention to analysis and deduction as well as rational logic and judgment, with emphasis on permutation and combination by inorganic rational analysis, advocating opposites in a contradiction, and stressing the individuality, discontinuity, tangibility and combinability in terms of conception of nature. Their paintings adopt focus perspective of geometry to display instant static and three-dimensional effects with the painter's viewpoint remain unchanged. They take advantage of triangular prism to decompose sunlight into all the colors of rainbow to research colors, and they analysis in-depth the wave length and amplitude of various spectrums. To draw a character, they start form dissecting corpses, and by making specimen of birds and beasts to draw them, and they call it paint from life. While painting, they tend to close one eye to observe, thinking only by this can they see completely.

And China is skilled in the thinking mode of Round Tao, entirety and dialectics with emphasis on intuition and epiphany of induction and sensibility, stressing the organic dialectical unity and universal relation of objects, advocating that harmony of contradictions shall be reflected on the conception of nature, striving for integrity, continuity, intangibility and metaplastic, stressing unity of human and nature. For example, domestic graphic representation is apt to vigorous and serious in terms of graphic design, and to express neat and order within irregularity, stressing completeness and unity within balance. However, western graphics stresses their outer frame background with pure geometry (circle, square, triangle and rhombus etc.) as a center. Meanwhile, it pays attention to the flexible, natural and unrestrained style with strong rhythmicity. Thirdly, different traditional culture may have different influence on design art in terms of impact to design art by traditional culture. We can regard design as art which is the same as philosophy and religion, belonging to one category of culture. As the existence of spirit, it is a form created by spirit value with certain concept as guiding principle. All the culture in various periods of history serve as a link between the past and future, so does design. Following 5000 thousand years of human civilization, such as Ancient Egypt Culture, Ancient Greek Culture, Ancient Rome Culture, European and American Culture in modern times, and even the Chinese Culture of same origin, even if we skim them, it is enough for us to learn about traditional culture's great charm, ubiquitous extensiveness, the continuity of direct or indirect line, and the imperceptible influence.

Design, namely combination of art and science, as a culture phenomenon, it may also be influenced by the traditional culture inevitably, which determines that different traditional culture background may inevitably generate different design art. For example, when designing the emblem of Beijing Olympic Games, designers has combined the characteristics of China and Beijing with the elements of Olympic Games skillfully, taking seal as main expression form, combining the art forms such as Chinese traditional seal and calligraphy with characteristics of sports, and made it deform exaggeratedly through artistic methods, which skillfully transforms it into a figure of a sportsman who is running forward and waving his hands for victory, meanwhile it has similarity in form to "Jing", a modern Chinese character, implying distinct Chinese charm.

\section{ReCognition of Aesthetics IdeA In Multi Design}

The world economy has entered into an era of competition and development globally, and first of all, as a product and tool of the economy, design will inevitably be involved in the process of multi idea identification globally, and it may also be regarded as a tool in the level of economy, culture, art and even the life style. Therefore, design inevitably possesses a global character. Meanwhile, design art is rooted in such fields as society, culture and moral of their own nation. Design activities of any nation cannot be done without specific social and cultural background and the nation spirit generated in the social and cultural environment at that times. Thus, design also possesses a national character.

As a result, Chinese art design has many same and different characteristics with foreign art design. Nowadays, science and technology developed rapidly, under the development trend of modern design diversification, and along with the intervention of new concept of living ways, the continuous renewal of thinking guidance and emotional expression method, the requirements for pursuing rational visual space is improving constantly, requiring the design art shall develop with the social development, various new design methods, material and design concept in terms of concept, function, meaning and formal expression, which is extremely consistent between the paces displayed in China and foreign countries.

\section{CONCLUSION}

While there are similarities and differences between Chinese and foreign design in terms of aesthetics judgment, design thinking, and the influences of traditional culture, design art is developing along with social development in terms of concept, function, meaning and formal expression. There is a gap between Chinese design art and that of western countries, and take western design as a reference can make our design art develop better. Meanwhile, western art also need to obtain the national culture feature needed by their design. Only by this mutual recognition, can Chinese and foreign design grow together.

\section{REFERENCES}

[1] Liu Guanzhong, Yin Dingbang. Design Methodology [M]. Higher Education Press, 2011 
[2] Xu HengChun. Design Aesthetics [M]. Tsinghua University Press, 2006

[3] Zhang Liguo. Design \& Art Aesthetics [M].Shandong Education Press, 2002

[4] Zhang Fa. Chinese and Western Aesthetics and Cultural Spirit [M].China Renmin University Press 2010

[5] Li Leshan. Aesthetics and Design [M].Xi'an Jiaotong University Press 2010

[6] Kan Tai-keung. Chinese and Western Civilization and Contemporary Chinese Design. [J].China Advertising, 2014, （04）

[7] Zhang Liguo. Modern Design Aesthetics [M]. Henan Fine Arts Publishing House, 2007

[8] Huang Qiangling. Discussion on Value Characteristic and Development of Modern Design Aesthetics [J].Art \& Design, 2004 (09)

[9] C.Panati.Extraordinary Origins of Everyday Things. [M]. Handiers, 1987

[10] Baddeley,A.D.Human Memory:Theory and Practice[M]. Boston,1998 